\title{
The Need for Nutrition Education Project (NNEdPro) - an educational intervention across UK Medical Schools to lay the foundations for good nutritional care
}

\author{
S. Ray ${ }^{1}$, R. Udumyan ${ }^{2}$, B. Thompson ${ }^{2}$, M. Rajput-Ray ${ }^{2}$, P. Sharma ${ }^{2}$, K. Lodge ${ }^{2}$, J. Gandy $^{3}$, \\ P. Douglas ${ }^{4}$, R. Broughton, S. Smart ${ }^{5}$ and R. Wilson ${ }^{6}$ \\ ${ }^{1}$ Medical School, UEA Norwich NR4 7TJ and Institute of Public Health, University of Cambridge CB2 OSP, ${ }^{2}$ NNEdPro \\ Steering Group and Faculty, C/O S Ray (NNEdPro Chairman), Selwyn College, Cambridge CB3 9DQ, ${ }^{3}$ The British Dietetic \\ Association, Great Charles St, Birmingham B3 3HT, ${ }^{4}$ School of Biomedical Sciences, University of Ulster, Coleraine, Co. \\ Londonderry BT52 1SA, ${ }^{5}$ Abbott Nutrition, Maidenhead, SL6 4XE and ${ }^{6}$ Nutrition and Dietetics Dept., Kings College \\ Hospital, London SE5 9RS
}

Hospital malnutrition in the UK has a prevalence estimate of $\sim 40 \%{ }^{(1)}$. Evidence suggests gaps in medical doctors' knowledge and skills in clinical nutrition ${ }^{(2)}$. The Council of Europe Alliance, UK, has recommended nutrition education for all medical students. NNEdPro was thus formed as an independent educational research, innovation and advocacy group, incorporated in the Department of Health's Nutrition Action Plan ${ }^{(3)}$. NNEdPro aimed to conduct an educational needs analysis and pilot a non-vertical curriculum intervention through an innovatively developed educational package in a national sample of tomorrow's doctors.

An intervention group of 100 senior/clinical medical students from 15 medical schools were recruited. A non-vertical educational package was delivered over $2 \mathrm{~d}$, incorporating interactive lectures, role-play, simulated consultations, small group work and mini-PBL. A spiral learning approach revisited topics in order to build upon consolidated basic concepts. Clinical nutrition knowledge, attitudes and practices (KAP) were assessed before and after intervention, and at 3 months, using a construct-validated questionnaire. Questionnaire items were randomised before and after intervention, to minimise recall bias. A student-reported evaluation of the educational intervention was also conducted and yielded favourable results.

Table 1. Nutrition knowledge, attitudes and practices

\begin{tabular}{lcrr}
\hline & Baseline* $(n$ 98 $)$ & Post-intervention* $(n$ 98) & $P$-value $\dagger$ \\
\hline Knowledge & $4.10 \pm 2.08$ & $4.96 \pm 1.75$ & $4.15 \pm 2.22$ \\
Attitude & $9.15 \pm 0.92$ & $10.84 \pm 0.71$ & $9.91 \pm 0.91$ \\
Practice & $15.2 \pm 2.57$ & $16.97 \pm 2.02$ & 0.0000 \\
KAP & $28.5 \pm 3.50$ & $32.77 \pm 2.79$ & 0.0000 \\
\hline
\end{tabular}

*Values are presented as mean difference $\pm \mathrm{SD} ; \dagger P$-value is from a one-way repeated measures analysis of variance (ANOVA)

Table 1 above demonstrates the key findings from NNEdPro, whereby a statistically significant change in Knowledge, Attitude and Practices scores were seen immediately after the intervention and this was sustained at 3 months. This project demonstrates the performance of the intervention aimed at improving nutrition education for tomorrow's doctors, and can serve as a model for Doctors and Dietitians to work in an effective interdisciplinary partnership when teaching medical students and health professionals.

Supported by an unrestricted educational grant from Abbott Nutrition and hosted by the British Dietetic Association.

1. BAPEN (2009) Nutrition Screening Survey in the UK in 2008: Hospital Care Homes, and Mental Health Units http://www.bapen.org.uk/pdfs/nsw/ nsw_report2008-09.pdf (accessed 29 January 2010).

2. Nightingale JMD \& Reeves J (1999) Knowledge about the assessment and management of undernutrition. Clin Nutr 18, $23-27$.

3. Department of Health (2007) Nutrition Action Plan. http://www.dh.gov.uk/en/publicationsandstatistics/publications/publicationspolicyandguidance/ dh_079931 (accessed 29 January 2010). 